Article

\title{
Evaluation of Extraction and Degradation Methods to Obtain Chickpeasaponin B1 from Chickpea (Cicer arietinum L.)
}

\author{
Kun Cheng, Hua Gao, Rong-Rong Wang, Yang Liu, Yu-Xue Hou, Xiao-Hong Liu, Kun Liu \\ and Wei Wang *
}

School of Pharmacy, Qingdao University, Qingdao 266021, Shandong, China; chengkun1990518@163.com (K.C.); gaohuaqy@126.com (H.G.); rrwang2012@163.com (R.-R.W.); buckuper@163.com (Y.L.); hyx19931008@163.com (Y.-X.H.); liuxiaohong1043@163.com (X.-H.L.); kunliu62@126.com (K.L.)

* Correspondence: qddxwangwei@qdu.edu.cn or w.w.wangwei@263.net; Tel.: +86-532-8699-1172

Academic Editor: Stefan Berger

Received: 19 January 2017; Accepted: 17 February 2017; Published: 21 February 2017

\begin{abstract}
The objective of this research is to implement extraction and degradation methods for the obtainment of 3-O-[ $\alpha$-L-rhamnopyranosyl-( $1 \rightarrow 2)-\beta$-D-galactopyranosyl] soyasapogenol B (chickpeasaponin B1) from chickpea. The effects of microwave-assisted extraction (MAE) processing parameters-such as ethanol concentration, solvent/solid ratio, extraction temperature, microwave irradiation power, and irradiation time-were evaluated. Using $1 \mathrm{~g}$ of material with $8 \mathrm{~mL}$ of $70 \%$ aqueous ethanol and an extraction time of $10 \mathrm{~min}$ at $70{ }^{\circ} \mathrm{C}$ under irradiation power $400 \mathrm{~W}$ provided optimal extraction conditions. Compared with the conventional extraction techniques, including heat reflux extraction (HRE), Soxhlet extraction (SE), and ultrasonic extraction (UE), MAE produced higher extraction efficiency under a lower extraction time. DDMP (2,3-dihydro-2,5-dihydroxy-6-methyl-4H-pyran-4-one) saponin can be degraded to structurally stable saponin $\mathrm{B}$ by the loss of its DDMP group. The influence of $\mathrm{pH}$ and the concentration of potassium hydroxide on transformation efficiency of the target compound was investigated. A solution of $0.25 \mathrm{M}$ potassium hydroxide in $75 \%$ aqueous ethanol was suitable for converting the corresponding DDMP saponins of chickpeasaponin B1. The implementation by the combining MAE technique and alkaline hydrolysis method for preparing chickpeasaponin B1 provides a convenient technology for future applications.
\end{abstract}

Keywords: Cicer arietinum L.; chickpea; chickpeasaponin B1; microwave-assisted extraction; alkaline hydrolysis

\section{Introduction}

Saponins, isolated from legumes, consist of a complex mixture of pentacyclic triterpenoid glycosides. For example, soybeans contain two different types of genuine saponins that are classified into group A saponins and 2,3-dihydro-2,5-dihydroxy-6-methyl-4H-pyran-4-one (DDMP) saponins [1,2]. Group A saponins that have soyasapogenol A $(3 \beta, 21 \beta, 22 \beta, 24$-tetrahydroxyolean12 -ene) as an aglycone are bisdesmosides, while DDMP saponins that have soyasapogenol $\mathrm{B}$ $(3 \beta, 22 \beta, 24-$ trihydroxyolean-12-ene) as an aglycone are monodesmosides [3-11]. DDMP saponins degrade into non-DDMP conjugated group B and E saponins, which is dependent on solvent, temperature, and storage time [12-14]. Group B saponins are the major saponins in processed soybean products, due to this conversion during extraction and processing [14]. Although soybean saponins have been analyzed, studies are ongoing to elucidate the chemical structures and biological activities of saponins in several other species of the legume family [15-20]. Chickpeas (Cicer arietinum L.), one 
of the wild progenitors of seven Neolithic founder crops and the third largest legume with respect to planting area for human consumption, are common in the Mediterranean region, the Middle East, South and Central America, India, Pakistan, Bangladesh, and China [21-23]. In addition to culinary usage, chickpeas have been accepted as a natural Uighur traditional medicine in Xinjiang (China) for over 2500 years [24]. Literature data reported that chickpeas contain mainly soyasaponin $\beta g$, a DDMP saponin, that was identified by fast atom bombardment mass-spectrometry [25]. A microwave-assisted extraction (MAE) method was developed for the extraction of soyasaponin $\beta \mathrm{g}$ from chickpea [26]. In the course of our study, the chickpeas purchased from an agricultural products market in Urumqi, China, were extracted using the MAE method reported by Kerem, et al. (2005). However, we found the retention time of the major component in the chickpea extract is different from that of soyasaponin $\beta \mathrm{g}$ standard by HPLC analysis. So, we also carried out a chemical investigation on $C$. arietinum, which resulted in the isolation of a new saponin, chickpeasaponin B1 (Figure 1). This was found to be a major component of the chickpea extract. The structure was determined as 3-O-[ $\alpha$-L-rhamnopyranosyl-( $1 \rightarrow 2)-\beta$-D-galactopyranosyl] soyasapogenol B on the basis of spectroscopic analysis as well as high resolution mass spectrometry and acid hydrolysis (NMR spectral data of chickpeasaponin B1 are available in the supplementary materials online). It was found to have a unique feature in legumes, that is, the presence of the $1 \rightarrow 2$ interglycosidic linkage between rhamnose and galactose. Chickpeasaponin B1 may be an artifact degraded from the corresponding DDMP saponins during the extraction and isolation procedures. Because of the structural stability of chickpeasaponin B1, we expect it is the source of chickpea functionality rather than DDMP saponin. Furthermore, the beneficial effects such as hypoglycemic, hepato-protective, anti-inflammatory, and anti-carcinogenic activities have been revealed using group B soyasaponins [27-30].

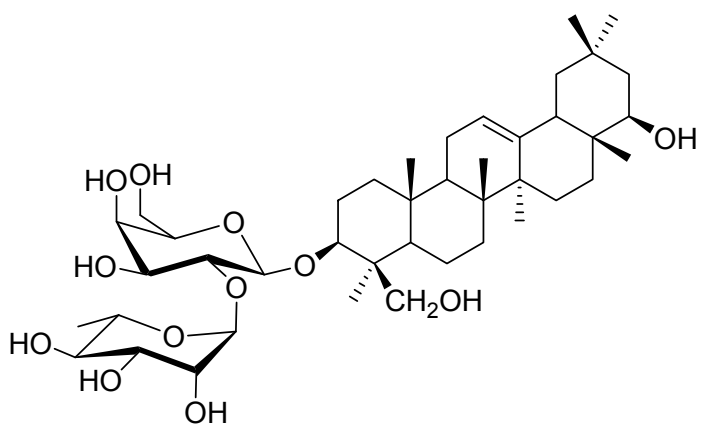

Figure 1. Structure of chickpeasaponin B1.

Saponins extracted from chickpeas could add value to the chickpea processing industry. The first step of processing is extraction, which involves separating the saponins from the cellular matrix of the chickpea. As an extraction technique, MAE utilizes the energy of microwaves to cause movement of molecules with a permanent dipole. This causes the internal temperature of each cell to rise rapidly and the cell to rupture due to the increased internal pressure. Thus, the extraction components are freely discharged. This process offers many advantages such as less solvent consumption, less extraction time, high extraction rate, and strong applicability to industrial settings [31,32]. In recent years, MAE technique has become very popular for extraction of bioactive constituents from natural products [33-42]. In this study, the objectives are to employ MAE to extract all the saponins in chickpeas and to compare rapid degradation conditions that convert corresponding DDMP saponins into chickpeasaponin B1. The extraction efficiency of MAE was compared with three other conventional extraction processes. The morphology of chickpea powder processed by MAE was observed using scanning electron microscopy. The effects of extraction and degradation processing parameters-such as ethanol concentration, solid/liquid ratio, extraction temperature, microwave irradiation power, irradiation time, $\mathrm{pH}$, and concentration of potassium hydroxide-were evaluated as well. The chickpeasaponin B1 was quantified by HPLC to evaluate extraction and degradation yields. 


\section{Results and Discussion}

\subsection{Optimization of MAE Conditions}

The univariate method was used to optimize the parameters of MAE including ethanol concentration, solid/liquid ratio, extraction temperature, microwave irradiation power, and irradiation time, any of which could extensively affect the extraction efficiency.

\subsubsection{Effect of Ethanol Concentration}

The selection of the most appropriate solvent for extracting the target compounds from the sample matrix is an essential step for developing any new extraction method. As a non-toxic and pollution-free choice, ethanol is regularly used for the extraction of natural products [43-45]. It has been observed that the addition of small amounts of water to the extraction solvent often helps to increase the extraction yield of the target compounds from the sample [44-46]. Therefore, aqueous ethanol was chosen as the extraction solvent. Different concentrations of ethanol (50\%, 60\%, 70\%, 80\%, 90\% and 100\%) were used as solvents to extract total saponins from chickpea. Other extraction conditions were held constant: the solid to liquid ratio of $1: 8(\mathrm{~g} / \mathrm{mL})$, microwave irradiation power of $400 \mathrm{~W}$, extraction temperature of $70{ }^{\circ} \mathrm{C}$, and extraction time of $10 \mathrm{~min}$. The results illustrated in Figure 2A showed that the highest extraction yield of chickpeasaponin B1 was obtained at 70\% aqueous ethanol. When the concentration of ethanol was between $50 \%$ and $70 \%$, the yield increased with the increasing concentration of ethanol. The yield declined when using $70 \%$ to $100 \%$ of ethanol. Thus, $70 \%$ aqueous ethanol was selected as the optimal solvent for the following extraction experiments.

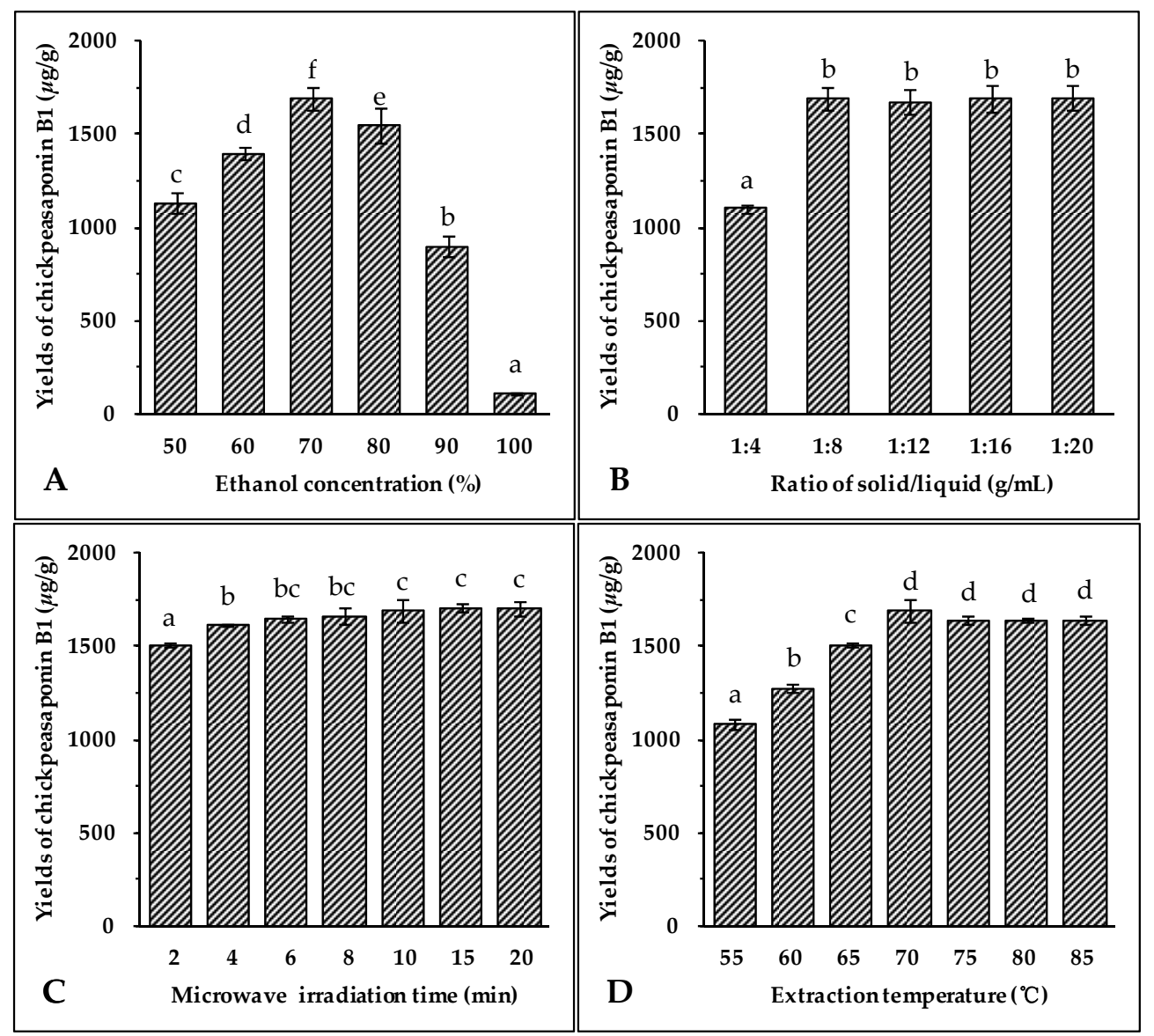

Figure 2. Cont. 


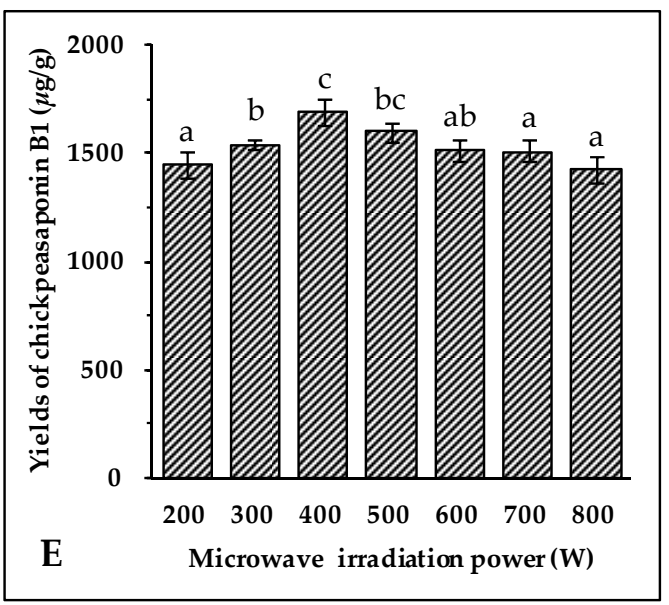

Figure 2. Effect of ethanol concentration (A); solid/liquid ratio (B); irradiation time (C); extraction temperature (D); and microwave irradiation power (E) on the yields of target compound. Data are expressed as the mean value \pm standard deviation (S.D.) of triplicate experiments. Data marked with different letters "a", " $\mathrm{b}$ ", "c ${ }^{\prime}$, “ $\mathrm{d}$ ", " $\mathrm{e}$ ", or " $\mathrm{f}$ " have significant differences, $p<0.05$, while those marked with the same letter denote no significant differences, $p>0.05$. Data marked with "ab" or "bc" have no significant differences from those marked with " $a$ " or " $b$ ", " $b$ " or " $c$ ", $p>0.05$, respectively.

\subsubsection{Effect of Solvent/Solid Ratio}

Large ratios of extraction solvent to substrate would lead to unnecessary waste, while small ratios may lead to incomplete extraction. Thus, the influence of the ratio of solvent to material on extraction efficiency of the target compound was evaluated next. The solvent used was $70 \%$ aqueous ethanol, microwave irradiation power was $400 \mathrm{~W}$, extraction temperature was $70{ }^{\circ} \mathrm{C}$, and time of extraction was $10 \mathrm{~min}$. Data shown in Figure 2B indicated an obvious increase of extraction yield of chickpeasaponin B1 when the solvent to solid ratio was increased from 4 to $8 \mathrm{~mL} / \mathrm{g}$. When the solvent to solid ratio was increased from 8 to $20 \mathrm{~mL} / \mathrm{g}$, however, no significant difference in the extraction yield of chickpeasaponin B1 was detected. For commercial application, a solvent to solid ratio of $8 \mathrm{~mL} / \mathrm{g}$ should be optimal for avoiding waste of solvent and excess work in the concentration process.

\subsubsection{Effect of Irradiation Time}

Microwave irradiation is able to generate sufficient energy in a short time, leading to an equilibrium between the objective constituents inside and outside the plant cell. The effect of the extraction time on chickpeasaponin B1 yield was investigated, and other experimental parameters were set as follows: ethanol concentration, 70\%; liquid to solid ratio, 8:1 (mL/g); microwave irradiation power, $400 \mathrm{~W}$; and extraction temperature, $70{ }^{\circ} \mathrm{C}$. The results shown in Figure $2 \mathrm{C}$ clearly indicated that the extraction yield of chickpeasaponin B1 increased from $1505.31 \pm 10.22 \mu \mathrm{g} / \mathrm{g}$ to $1692.27 \pm 63.72 \mu \mathrm{g} / \mathrm{g}$ when extraction time increased from 2 to $10 \mathrm{~min}$. However, the difference in the yield of chickpeasaponin B1 was not significant $(p>0.05)$ when the time of MAE increased from 10 to $20 \mathrm{~min}$. Because the diffusion front moved towards the interior of the tissues, the diffusion area reduced, diffusion distance increased, and the diffusion rate decreased accordingly [47]. Therefore, there was no obviously-observed yield change during the prolonged time period and $10 \mathrm{~min}$ was chosen as optimal extraction time.

\subsubsection{Effect of Extraction Temperature}

Extraction temperature impacts the solubility and mass transfer rate of the target compound. Seven different temperatures $\left(55,60,65,70,75,80\right.$ and $\left.85^{\circ} \mathrm{C}\right)$ were selected to evaluate the influence of the temperature on the extraction efficiency of chickpeasaponin B1 from chickpea. Seven groups of 
samples were pretreated with the optimal parameters obtained in the previous assays: $70 \%$ aqueous ethanol, $10 \mathrm{~min}$ of extracting time, and an 8:1 ratio of solvent to solid. As the temperature increased from $55{ }^{\circ} \mathrm{C}$ to $70{ }^{\circ} \mathrm{C}$, the yields of chickpeasaponin B1 significantly increased (Figure 2D). However, when the temperature exceeded $70{ }^{\circ} \mathrm{C}$, the yields of chickpeasaponin B1 decreased. This extreme temperature might have caused the chickpea powder with high starch content to partially cook, thereby causing the loss of chickpeasaponin B1 [44]. So, $70{ }^{\circ} \mathrm{C}$ was found to be the extraction temperature that produced the highest yield.

\subsubsection{Effect of Irradiation Power}

Microwave energy affects the molecular interactions between the solvent and the objective compounds significantly. Under the above optimal conditions of extraction, $70 \%$ aqueous ethanol solvent, 10 min of irradiation, an 8:1 ratio of liquid to material, and an extraction temperature of $70{ }^{\circ} \mathrm{C}$, the experiment was carried out at 200, 300, 400, 500, 600, 700, and $800 \mathrm{~W}$, respectively. As shown in Figure 2E, when the irradiation power increased from $200 \mathrm{~W}$ to $400 \mathrm{~W}$, the extraction yields of chickpeasaponin B1 increased significantly, while the yields showed the opposite trend when the power increased from $400 \mathrm{~W}$ to $800 \mathrm{~W}$. It is speculated that the superfluous energy offered by high irradiation power disturbed the molecular interaction, which was adversarial to the extraction of chickpeasaponin B1. Therefore, it was appropriate to select $400 \mathrm{~W}$ as the practical microwave irradiation power with the yield of $1692.27 \pm 63.72 \mu \mathrm{g} / \mathrm{g}$.

\subsection{Comparison of Different Extraction Methods}

In order to evaluate the extraction efficiency of MAE, the extraction yield was compared with conventional extraction methods like heat reflux extraction (HRE), Soxhlet extraction (SE), and ultrasonic extraction (UE). The extraction results of chickpeasaponin B1 with varying times and extraction methods are shown in Table 1 . The results showed that, compared with HRE at 120 min, SE at $210 \mathrm{~min}$, and UE at $90 \mathrm{~min}$, the highest extraction yield of chickpeasaponin B1 was achieved by MAE at $20 \mathrm{~min}$. MAE yielded chickpeasaponin B1 $(1692.27 \pm 63.72 \mu \mathrm{g} / \mathrm{g})$ only when the extraction time reached $10 \mathrm{~min}$. For HRE, when the extraction time exceeded $60 \mathrm{~min}$, the yield of chickpeasaponin B1 tended to remain constant. Times of $210 \mathrm{~min}$ and $90 \mathrm{~min}$ were needed for SE and UE to produce their maximum extraction yield of $1079.11 \pm 59.50 \mu \mathrm{g} / \mathrm{g}$ and $871.28 \pm 27.92 \mu \mathrm{g} / \mathrm{g}$, respectively, and these were lower than that of MAE $(p<0.01)$. MAE took less time and had a higher extraction yield than other methods. Therefore, MAE was found to be suitable for the extraction of total saponins from chickpea.

\subsection{Scanning Electron Microscopy Observation}

In order to evaluate the morphological alteration after the MAE process, the samples were observed with SEM. Figure 3 shows micrographs of a sample of raw material (RM) and a sample after MAE for $10 \mathrm{~min}$. The micrograph of the RM revealed numerous spherical or elliptical particles. Compared with RM, chickpea powder after MAE treatment contained the amorphous material, spherical particles, and clear fragmentation of cell walls. This observation confirmed that, during microwave irradiation, rapid heating of polar molecules in the material and the solvent led to a rapid expansion of the solvent volume, which increased the pressure within the cells and caused an explosive release of the substances inside of the plant cells [48]. 
Table 1. Extraction efficiency of four processes on chickpeasaponin B1, including microwave-assisted extraction (MAE), heat reflux extraction (HRE), Soxhlet extraction (SE), and ultrasonic extraction (UE).

\begin{tabular}{cccc}
\hline MAE & \multicolumn{3}{c}{ HRE } \\
\hline Extraction Time (min) & Yields $(\mu \mathrm{g} / \mathrm{g})$ & Extraction Time $(\mathbf{m i n})$ & Yields $(\mu \mathrm{g} / \mathrm{g})$ \\
\hline 2 & $1505.31 \pm 10.22$ & 10 & $1277.34 \pm 19.39$ \\
4 & $1613.20 \pm 7.80$ & 20 & $1433.34 \pm 17.94$ \\
6 & $1651.91 \pm 17.64$ & 30 & $1490.64 \pm 70.29$ \\
8 & $1666.89 \pm 43.85$ & 60 & $1557.67 \pm 54.23$ \\
10 & $1692.27 \pm 63.72$ & 90 & $1610.18 \pm 23.13$ \\
15 & $1710.83 \pm 20.88$ & 120 & $1628.20 \pm 33.29$ \\
20 & $1703.22 \pm 35.60$ & 150 & $1595.12 \pm 35.37$ \\
SE & & UE & \\
\hline Extraction Time (min) & Yields $(\mu \mathrm{g} / \mathrm{g})$ & Extraction Time (min) & Yields $(\mu \mathrm{g} / \mathrm{g})$ \\
\hline 30 & $212.28 \pm 10.96$ & 10 & $434.41 \pm 46.11$ \\
60 & $246.80 \pm 42.79$ & 20 & $479.95 \pm 20.65$ \\
90 & $373.81 \pm 52.17$ & 30 & $675.25 \pm 26.80$ \\
120 & $493.67 \pm 40.35$ & 40 & $690.49 \pm 29.26$ \\
150 & $599.63 \pm 44.92$ & 50 & $708.59 \pm 35.87$ \\
210 & $776.00 \pm 67.17$ & 60 & $773.49 \pm 22.92$ \\
\hline
\end{tabular}

Data are expressed as the mean value $( \pm \mathrm{SD})$ of three independent experiments.

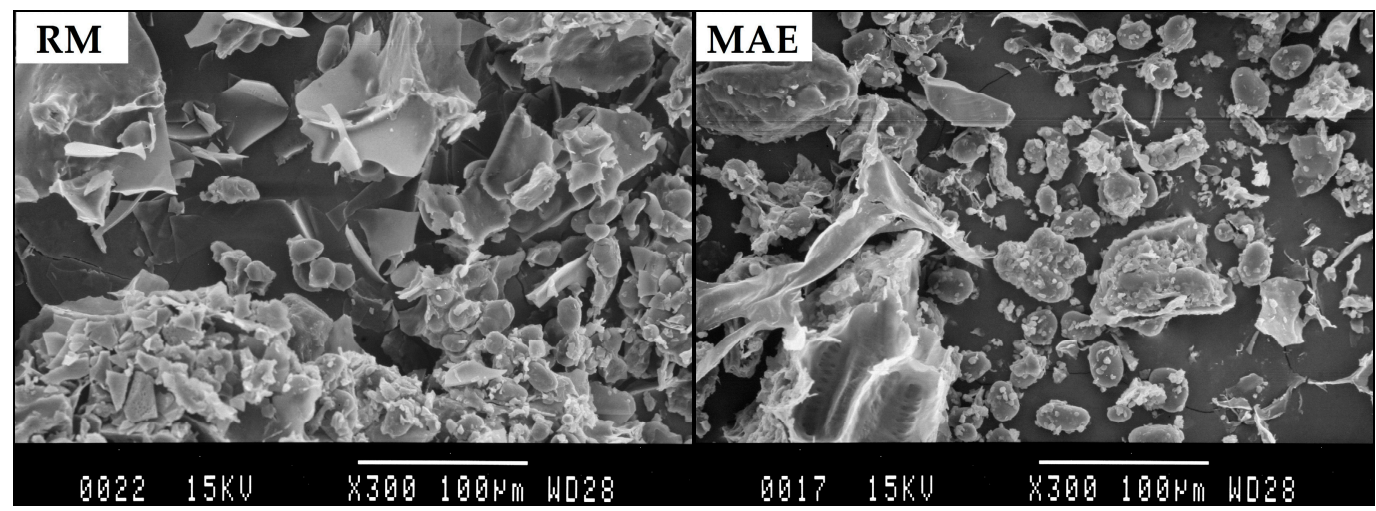

Figure 3. Left, a scanning electron microscopy image of a sample of raw material (RM) and right, the sample processed by MAE.

\subsection{Comparison of Degradation Methods}

To degrade the corresponding DDMP saponin to chickpeasaponin B1, the removal of the DDMP moiety from the structure had to be targeted. The effect of $\mathrm{pH}$ on the stability of DDMP saponin was studied in this experiment. As shown in Figure 4, it was found that alkaline hydrolysis in aqueous ethanol produced the maximum amount of chickpeasaponin B1 when compared to aqueous ethanol and acid hydrolysis in aqueous ethanol. This result was partly consistent with the findings reported by Zhang et al. (2009), who transformed the DDMP-conjugated group B soyasaponins into the non-DDMP-conjugated soyasaponins I and III [12]. The amount of chickpeasaponin B1 produced by basic $75 \%$ aqueous ethanol $(\mathrm{pH}=12)$ increased the level of chickpeasaponin B1 by approximately $1079.67 \mu \mathrm{g} / \mathrm{g}$ chickpea or an increased percentage of $272.74 \%$. To select a proper concentration of potassium hydroxide in $75 \%$ aqueous ethanol that would guarantee completion degradation of corresponding DDMP saponins of chickpeasaponin B1, hydrolysis dynamics curves were investigated (Figure 5). It was observed that when the potassium hydroxide concentrations were $0.1 \%$ and $0.2 \%$, the converting rates of the corresponding DDMP saponins reached their maximum with the yields of chickpeasaponin B1 of $530.14 \pm 18.37 \mu \mathrm{g} / \mathrm{g}$ and $1072.72 \pm 51.34 \mu \mathrm{g} / \mathrm{g}$ at $48 \mathrm{~h}$, were produced 
respectively. When the concentration was increased to $0.5 \%$, catalytic efficiency was significantly enhanced, and most of the corresponding DDMP saponins of chickpeasaponin B1 were transformed in $12 \mathrm{~h}$. The comparison between the first and the last chromatogram in Figure 6 indicated that the corresponding DDMP saponins had been hydrolyzed completely to chickpeasaponin B1.

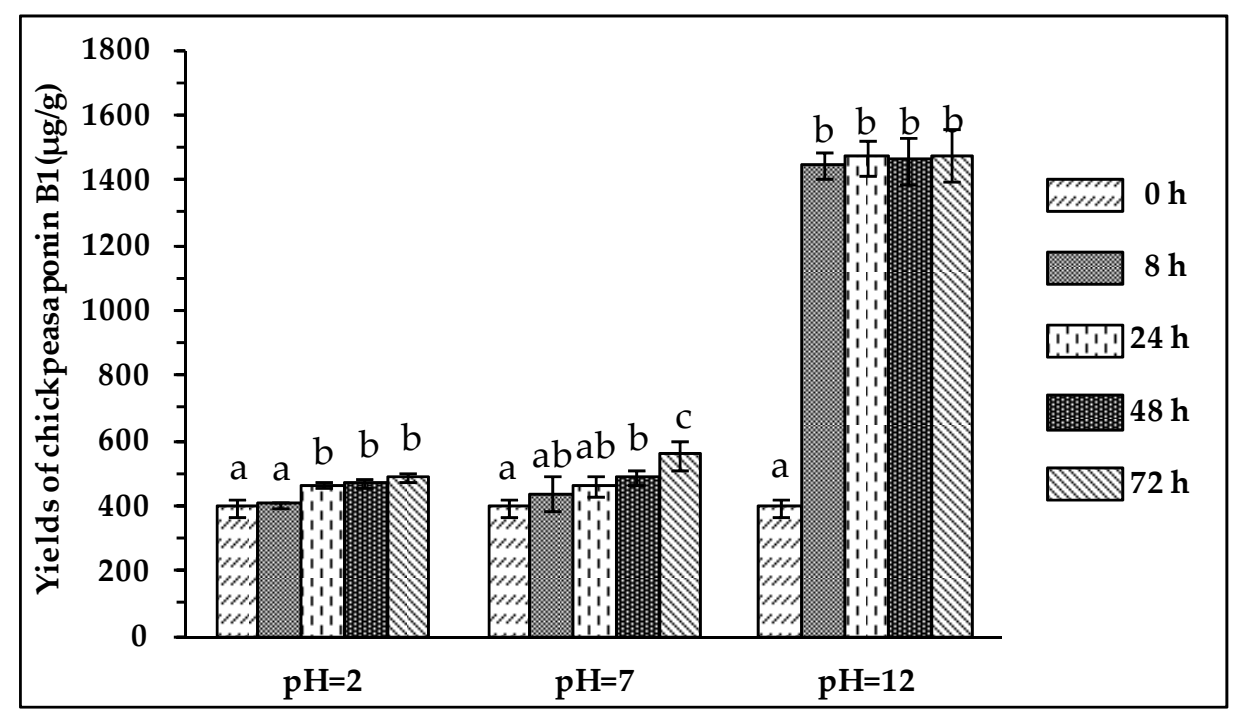

Figure 4. Effect of $\mathrm{pH}$ on the yields of target compound. Data are expressed as the mean value \pm standard deviation (S.D.) of triplicate experiments. Data marked with different letters " $a$ ", " $b$ ", or " $c$ " have significant differences, $p<0.05$, while those marked with the same letter denote no significant difference, $p>0.05$. Data marked with "ab" have no significant differences with those marked with "a" or " $\mathrm{b}$ ", $p>0.05$, respectively.

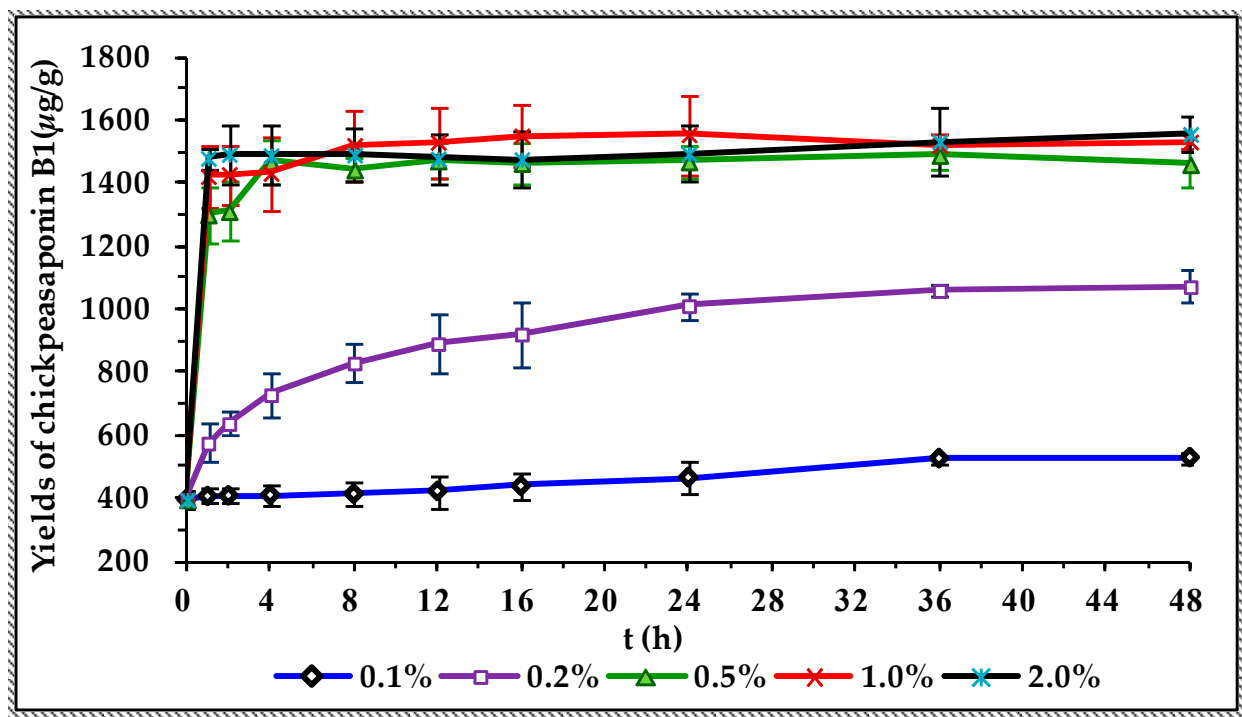

Figure 5. Hydrolysis dynamic curves of the total saponins of chickpea catalyzed by potassium hydroxide in $75 \%$ aqueous ethanol with different concentrations of $0.1 \%, 0.2 \%, 0.5 \%, 1.0 \%, 2.0 \%$. Data are expressed as the mean value \pm standard deviation (S.D.) of triplicate experiments. 

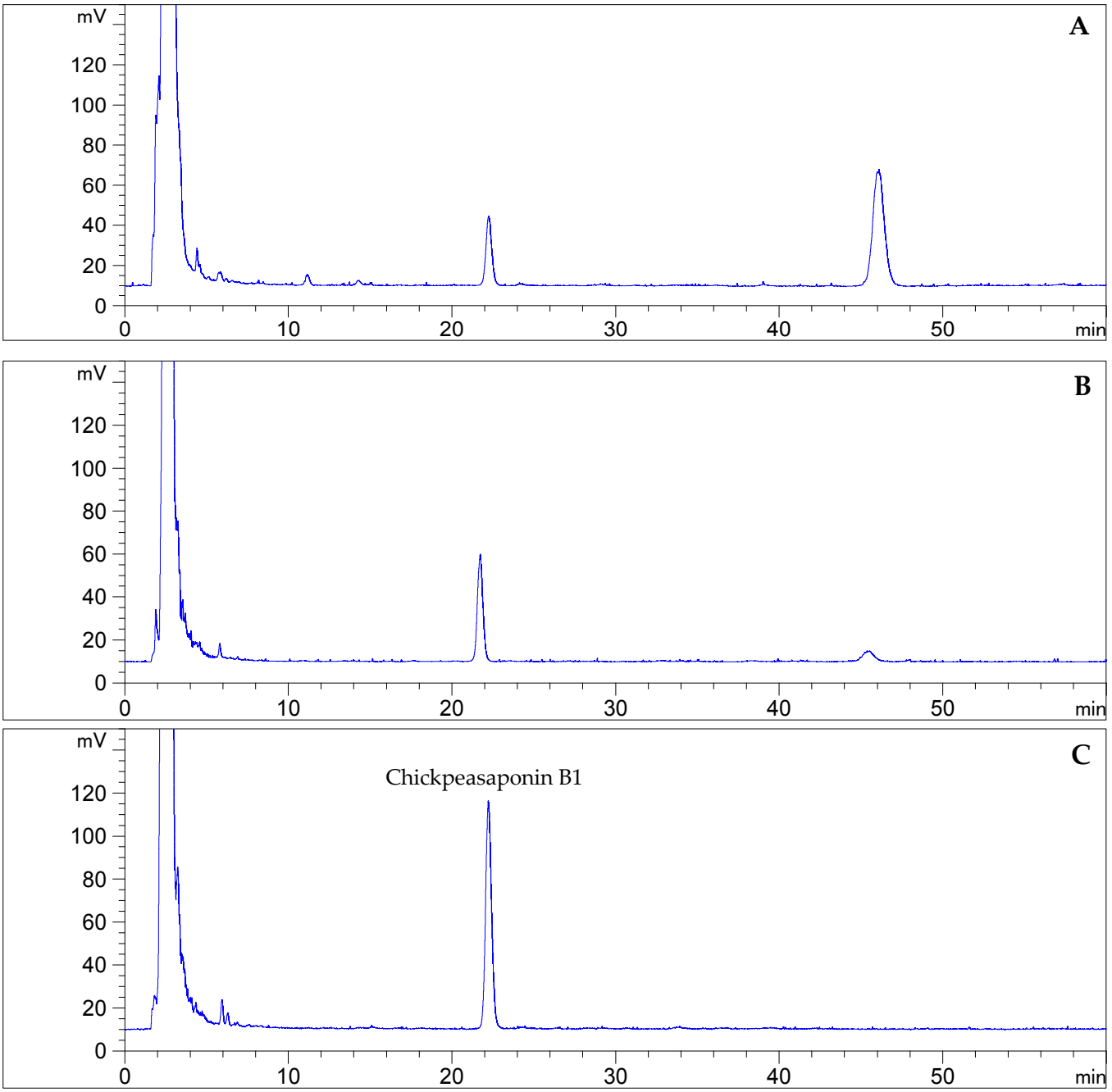

Figure 6. Quantification by HPLC-ELSD of chickpeasaponin B1 obtained from chickpea extracted by MAE (A); the total saponins degraded by potassium hydroxide in $75 \%$ aqueous ethanol $(1 \%, \mathrm{~g} / \mathrm{mL})$ for $0.5 \mathrm{~h}(\mathbf{B})$; and $12 \mathrm{~h} \mathrm{(C)}$.

\section{Materials and Methods}

\subsection{Materials and Reagents}

Chickpeas were purchased from an agricultural products market in Urumqi, China, and authenticated by Prof. Ying-Xia Li, Qingdao University. A voucher specimen was deposited in Natural Products Research Laboratory, School of Pharmacy, Qingdao University. Chickpeas were ground into a powder using an electric disintegrator (FW177, Tianjin Taisite Instruments Co., Ltd., Tianjin, China). The ground powder was pass through a stainless steel sieve for homogenization (20 mesh) and stored in airtight bags at $4{ }^{\circ} \mathrm{C}$ for later use. Reference compound chickpeasaponin B1 with more than $98 \%$ purity was isolated and purified from the seeds of $C$. arietinum in our laboratory. The structure was determined as 3-O-[ $\alpha$-L-rhamnopyranosyl-( $1 \rightarrow 2)-\beta$-D-galactopyranosyl] soyasapogenol B on the basis of spectroscopic analysis as well as high resolution mass spectrometry and acid hydrolysis. Acetonitrile and methanol of chromatographic grade were bought from Tedia Company Inc. (Fairfield, OH, USA). Deionized water was purified by a Milli-Q water purification system from Millopore (Bedford, MA, USA). All reagents and samples prepared for chromatographic analysis were filtered through $0.45 \mu \mathrm{m}$ membranes (Jinteng Experimental Equipment Co., Ltd., Tianjin, China) before use. All other reagents obtained from Fuyu Fine Chemical Co., Ltd. (Tianjin, China) were of analytical grade. 


\subsection{HPLC Analysis}

HPLC analyses were performed on an Agilent 1260 Infinity HPLC system equipped with a G1311C quaternary pump, a G1329B autosampler, a G1316A thermostatted column compartment, and a G4260B evaporative light scattering detector (ELSD) coupled with an analytical workstation (Agilent Technologies, Inc., Santa Clara, CA, USA). Chromatographic separation was achieved on a YMC-Pack ODS column $(250 \mathrm{~mm} \times 4.6 \mathrm{~mm}$ i.d., $5 \mu \mathrm{m}$, YMC Co., Ltd., Kyoto, Japan). Methanol-acetonitrile-water containing $2 \%(v / v)$ acetic acid $(40: 25: 35, v / v / v)$ was used as the mobile phase. The flow rate was $1.0 \mathrm{~mL} \cdot \mathrm{min}^{-1}$, the injection volume was $5 \mu \mathrm{L}$, and the column temperature was maintained at $25^{\circ} \mathrm{C}$. For ELSD detection, the carrier gas was air, the evaporating tube and atomization tube temperatures were set at $110^{\circ} \mathrm{C}$ and $80^{\circ} \mathrm{C}$, respectively, with gas flow rate of $1.4 \mathrm{~L} \cdot \mathrm{min}^{-1}$. The chromatographic peak of chickpeasaponin B1 was verified by comparing its retention time with the reference standard. The content was calculated from the working calibration curve constructed by plotting the logarithm of peak areas vs the logarithm of the amounts injected series reference standard solutions.

\subsection{Comparison of Extraction Methods}

\subsubsection{Microwave-Assisted Extraction (MAE)}

MAE was carried out in a MAS-II microwave auxiliary reaction/extraction system (Shanghai Sineo Microwave Chemistry Technology Co., Ltd., Shanghai, China). An accurately weighed $10 \mathrm{~g}$ sample of chickpea powder was mixed with $80 \mathrm{~mL}$ of $70 \%$ aqueous ethanol in a special microwave three-neck flask (300 mL), which was put in the microwave-assisted extraction apparatus and connected to a condensing unit and temperature control device for microwave-assisted extraction. The extractions were conducted at a temperature of $70{ }^{\circ} \mathrm{C}$ with a microwave irradiation power of $400 \mathrm{~W}$ for $2,4,6,8$, 10,15 , and $20 \mathrm{~min}$.

\subsubsection{Heat Reflux Extraction (HRE)}

An accurately weighed $10 \mathrm{~g}$ sample of chickpea powder was moved into a round-bottomed flask equipped with a water condenser tube. The $70 \%$ aqueous ethanol was used as the extraction solvent, and the ratio of solvent to material was 8:1. The reflux extractions were carried out at a temperature of $90^{\circ} \mathrm{C}$ in a thermostat boiling-water bath, and with the time periods of 10, 20, 30, 60, 90, 120, and $150 \mathrm{~min}$.

\subsubsection{Soxhlet Extraction (SE)}

An accurately weighed $10 \mathrm{~g}$ sample of chickpea powder was packed into a cardboard tube to a suitable height using filter paper. It was then placed into a Soxhlet extraction apparatus. The Soxhlet extraction apparatus was connect to a reflux condenser, fixed in a thermostat boiling-water bath followed by the addition of $80 \mathrm{~mL}$ of $70 \%$ aqueous ethanol. The experimental temperature was set at $90{ }^{\circ} \mathrm{C}$ for $30,60,90,120,150,180$, and $210 \mathrm{~min}$.

\subsubsection{Ultrasonic Extraction (UE)}

To study extraction by ultrasonication, an accurately weighed $10 \mathrm{~g}$ sample of chickpea powder was transferred in a flat-bottomed flask containing $70 \%$ aqueous ethanol $(80 \mathrm{~mL})$. The flask was immersed in an ultrasonicator bath (KQ-500E, Kunshan Ultrasonic Instruments Co., Ltd., Kunshan, China, $40 \mathrm{kHz}, 500 \mathrm{~W}$ ) and ultrasonicated for 10, 20, 30, 40, 50, 60, 90, and $120 \mathrm{~min}$.

\subsection{Optimization of MAE Conditions}

In order to determine the best extracting medium for saponins in chickpea, a $10 \mathrm{~g}$ sample was mixed with aqueous ethanol in concentrations of $50 \%, 60 \%, 70 \%, 80 \%, 90 \%$, and $100 \%$, respectively. The best extracting solvent was examined and the ratios of solvent to material with the proportions 
of $4,8,12,16$, and $20(v / w, \mathrm{~mL} / \mathrm{g})$ were tested. Optimization of irradiation time was performed with the designed periods of $2,4,6,8,10$, and $12 \mathrm{~min}$. To study the effects of extraction temperature and microwave irradiation power, $10 \mathrm{~g}$ of powder was subjected to $80 \mathrm{~mL}$ of $70 \%$ aqueous ethanol and irradiated at different temperatures including $55,60,65,70,75,80$, and $85{ }^{\circ} \mathrm{C}$ with microwave irradiation power of $400 \mathrm{~W}$. Different power levels of 200, 300, 400, 500, 600, 700, and $800 \mathrm{~W}$ at the extraction temperature of $70{ }^{\circ} \mathrm{C}$ were also tested.

\subsection{Extract Concentration}

Once the extraction processes were accomplished, the extracted solutions were filtered and $50 \mathrm{~mL}$ of this solution were concentrated using a rotary evaporator (N-1001, Tokyo Rikakikai Co., Ltd., Tokyo, Japan) and stored at $-20^{\circ} \mathrm{C}$ for further testing.

\subsection{Comparison of Degradation Methods}

The solvent-free extract was dissolved and diluted with acidic $75 \%$ aqueous ethanol $(\mathrm{pH}=2)$ neutral $75 \%$ aqueous ethanol $(\mathrm{pH}=7)$, and basic $75 \%$ aqueous ethanol $(\mathrm{pH}=12)$ in a $10 \mathrm{~mL}$ volumetric flask, respectively. The mixture was hydrolyzed for the time periods of $8,24,48$, and $72 \mathrm{~h}$ at room temperature. To investigate the effect of the concentration of potassium hydroxide in $75 \%$ aqueous ethanol, the sample was subjected to $10 \mathrm{~mL}$ of various concentrations of sodium hydroxide $(0.1 \%, 0.2 \%$, $0.5 \%, 1.0 \%, 2.0 \%$ ) and incubated for $1,2,4,8,12,16,24,36$, and $48 \mathrm{~h}$ at room temperature.

\subsection{Statistical Analysis}

Data were expressed as the mean \pm standard deviation (S.D.) of triplicate determination. Statistical calculations were analyzed by one-way analysis of variance using the SPSS version 13.0 software (SPSS, Inc., Chicago, IL, USA). A value of $p<0.05$ was considered statistically significant.

\section{Conclusions}

In summary, an efficient process for obtainment of chickpeasaponin B1 from chickpeas was established using the combining MAE technique and alkaline hydrolysis method. The procedures were optimized, validated, and compared with other conventional processes. High quality product containing mainly chickpeasaponin B1 was produced with less production time duration. Therefore, the results indicated the feasibility for future applications.

Supplementary Materials: Supplementary materials are available online.

Acknowledgments: The authors acknowledge the financial support from the start-up grant from Qingdao University.

Author Contributions: The contributions of the respective authors are as follows: K.C., R.-R.W, Y.-X.H., and X.-H.L. performed the experiments; K.L. analyzed the data; K.C. and Y.L. wrote the paper. H.G. contributed to checking and confirming all the procedures of experiments. This study was performed based on the design of W.W., the corresponding author.

Conflicts of Interest: The authors declare no conflict of interest.

\section{References}

1. Chitisankul, W.T.; Shimada, K.; Omizu, Y.; Uemoto, Y.; Varanyanond, W.; Tsukamoto, C. Mechanism of DDMP-saponin degradation and maltol production in soymilk preparation. LWT Food Sci. Technol. 2015, 64, 197-204. [CrossRef]

2. Krishnamurthy, P.; Tsukamato, C.; Singh, R.J.; Lee, J.D.; Kim, H.S.; Yang, S.H.; Chung, G. The Sg-6 saponins, new components in wild soybean (Glycine soja Sieb. and Zucc.): Polymorphism, geographical distribution and inheritance. Euphytica 2014, 198, 413-424. [CrossRef]

3. Kitagawa, I.; Saito, M.; Taniyama, T.; Yoshikawa, M. Saponin and sapogenol. XXXIX. Structure of soyasaponins $\mathrm{A}_{1}$, a bisdeamoside of soyasapogenol A, from soybean, the seeds of Glycine max MERRIL. Chem. Pharm. Bull. 1985, 33, 1069-1076. [CrossRef] 
4. Kitagawa, I.; Wang, K.H.; Taniyama, T.; Yoshikawa, M. Saponin and sapogenol. XLI. Reinvestigation of the structures of soyasapogenols A, B, and E, oleanene-sapogenols from soybean. Structures of soyasaponins I, II, and III. Chem. Pharm. Bull. 1988, 36, 153-161. [CrossRef]

5. Taniyama, T.; Nagahama, Y.; Yoshikawa, M.; Kitagawa, I. Saponin and sapogenol. XLIII. Acetyl-soyasaponins $\mathrm{A}_{4}, \mathrm{~A}_{5}$, and $\mathrm{A}_{6}$, new astringent bisdeamosides of soyasapogenol $\mathrm{A}$, from Japanese soybean, the seeds of Glycine max MERRIL. Chem. Pharm. Bull. 1988, 36, 2829-2839. [CrossRef]

6. Shiraiwa, M.; Yamauchi, F.; Harada, K.; Okubo, K. Inheritance of "group A saponin" in soybean seed. Agric. Biol. Chem. 1990, 54, 1347-1352.

7. Shiraiwa, M.; Kudo, S.; Shimoyamada, M.; Harada, K.; Okubo, K. Composition and structure of "group A saponin" in soybean seed. Agric. Biol. Chem. 1991, 55, 315-322.

8. Tsukamoto, C.; Kikuchi, A.; Kudou, S.; Harada, K.; Kitamura, K.; Okubo, K. Group A acetyl saponin-deficient mutant from the wild soybean. Phytochemistry 1992, 31, 4139-4142. [CrossRef]

9. Kudou, S.; Tonomura, M.; Tsukamoto, C.; Shimoyamada, M.; Uchida, T.; Okubo, K. Isolation and structural elucidation of the major genuine soybean saponin. Biosci. Biotechnol. Biochem. 1992, 56, 142-143. [CrossRef] [PubMed]

10. Kudou, S.; Tonomura, M.; Tsukamoto, C.; Uchida, T.; Sakabe, T.; Tamura, N.; Okubo, K. Isolation and structural elucidation of DDMP-conjugated soyasaponins as genuine saponins from soybean seeds. Biosci. Biotechnol. Biochem. 1993, 57, 546-550. [CrossRef]

11. Kudou, S.; Tonomura, M.; Tsukamoto, C.; Tsukamoto, C.; Uchida, T.; Yoshikoshi, M.; Okubo, K. Structural elucidation and physiological properties of genuine soybean saponina. ACS Symp. 1994, 547, 340-348.

12. Zhang, W.; Teng, S.P.; Popovich, D.G. Generation of group B soyasaponins I and III by hydrolysis. J. Agric. Food Chem. 2009, 57, 3620-3625. [CrossRef] [PubMed]

13. Daveby, Y.D.; Aman, P.; Betz, J.M.; Musser, S.M. Effect of storage and extraction on ratio of soyasaponin I to 2,3-dihydro-2,5-dihydroxy-6-methyl-4-pyrone-conjugated soyasaponin I in dehulled peas (Pisum sativum L.). J. Sci. Food Agric. 1998, 78, 141-146. [CrossRef]

14. Hu, J.; Lee, S.O.; Hendrich, S.; Murphy, P.A. Quantification of the group B soyasaponins by high performance liquid chromatography. J. Agric. Food Chem. 2002, 50, 2587-2594. [CrossRef] [PubMed]

15. Reim, V.; Rohn, S. Characterization of saponins in peas (Pisumsativum L.) by HPTLC coupled to mass spectrometry and a hemolysis assay. Food Res. Int. 2015, 76, 3-10. [CrossRef]

16. Llorent-Martínez, E.J.; Spínola, V.; Gouveia, S.; Castilho, P.C. HPLC-ESI-MS ${ }^{n}$ characterization of phenolic compounds, terpenoidsaponins, and other minor compounds in Bituminaria bituminosa. Ind. Crop. Prod. 2015, 69, 80-90. [CrossRef]

17. Taylor, W.G.; Sutherland, D.H.; Richards, K.W.; Zhang, H.X. Oleanane triterpenoid saponins of Caragana arborescens and their quantitative determination. Ind. Crop. Prod. 2015, 77, 74-80. [CrossRef]

18. Lee, S.S.; Esa, N.M.; Loh, S.P. In vitro inhibitory activity of selected legumes against pancreatic lipase. J. Food Biochem. 2015, 39, 485-490. [CrossRef]

19. Liu, R.; Xu, B.J. Inhibitory effects of phenolics and saponins from commonly consumed food legumes in China against digestive enzymes pancreatic lipase and $\alpha$-glycosidase. Int. J. Food Prop. 2015, 18, 2246-2255. [CrossRef]

20. Melek, F.R.; Kassem, I.A.A.; Miyase, T.; Fayad, W. Caspicaosides E-K, triterpenoid saponins and cytotoxic acylated saponins from fruits of Gleditsia caspica Desf. Phytochemistry 2014, 100, 110-119. [CrossRef] [PubMed]

21. Lev-Yadun, S.; Gopher, A.; Abbo, S. The cradle of agriculture. Science 2000, 288, 1602-1603. [CrossRef] [PubMed]

22. Cortés-Giraldo, I.; Megías, C.; Alaiz, M.; Girón-Calle, J.; Vioque, J. Purification of free arginine from chickpea (Cicer arietinum) seeds. Food Chem. 2016, 192, 114-118. [CrossRef] [PubMed]

23. Archak, S.; Tyagi, R.K.; Harer, P.N.; Mahase, L.B.; Singh, N.; Dahiya, O.P.; Nizar, M.A.; Singh, M.; Tilekar, V.; Kumar, V. Characterization of chickpea germplasm conserved in the Indian National Genebank and development of a core set using qualitative and quantitative trait data. Crop J. 2016, 4, 417-426. [CrossRef]

24. Zhao, S.H.; Zhang, L.P.; Gao, P.; Shao, Z.Y. Isolation and characterisation of the isoflavones from sprouted chickpea seeds. Food Chem. 2009, 114, 869-873. [CrossRef]

25. Price, K.R.; Eagles, J.; Fenwick, G.R. Saponin composition of 13 varieties of legume seed using fast atom bombardment mass-spectrometry. J. Sci. Food Agric. 1988, 42, 183-193. [CrossRef] 
26. Kerem, Z.; German-Shashoua, H.; Yarden, O. Microwave-assisted extraction of bioactive saponins from chickpea (Cicer arietinum L). J. Sci. Food Agric. 2005, 85, 406-412. [CrossRef]

27. Tanaka, M.; Watanabe, T.; Uchida, T.; Kanazawa, T.; Osanai, T.; Okumura, K. Hypoglycemic effect of soyasaponin B extracted from hypocotyl on the increasing blood glucose in diabetic mice (KK-Ay/Ta). J. Jpn. Soc. Clin. Nutr. 2006, 27, 358-366.

28. Kinjo, J.; Imagire, M.; Udayama, M.; Arao, T.; Nohara, T. Structure-hepatoprotective relationships study of soyasaponin I-IV having soyasapogenol B as aglycone. Planta Med. 1998, 64, 233-236. [CrossRef] [PubMed]

29. Lee, I.; Park, Y.; Joh, E.; Kim, D. Soyasaponin I attenuates TNBS-induced colitis in mice by inhibiting NF- $\mathrm{B}$ pathway. J. Agric. Food Chem. 2010, 58, 10929-10934. [CrossRef] [PubMed]

30. Ellington, A.A.; Berhow, M.; Singletary, K.W. Induction of macroautophagy in human colon cancer cell by soybean B-group triterpenoid saponins. Carcinogensis 2005, 26, 159-167. [CrossRef] [PubMed]

31. Pinela, J.; Prieto, M.A.; Carvalho, A.M.; Barreiro, M.F.; Oliveira, M.B.P.P.; Barros, L.; Ferreira, L.C.F.R. Microwave-assisted extraction of phenolic acids and flavonoids and production of antioxidant ingredients from tomato: A nutraceutical-oriented optimization study. Sep. Purif. Technol. 2016, 164, 114-124. [CrossRef]

32. Zou, T.B.; Wu, H.F.; Li, H.W.; Jia, Q.; Song, Y. Comparison of microwave-assisted and conventional extraction of mangiferin from mango (Mangifera indica L.) leaves. J. Sep. Sci. 2013, 36, 3457-3462. [PubMed]

33. Renoe, B.W. Microwave-assisted extraction. Am. Lab. 1994, 26, 34-40.

34. Eskilsson, P.C.; Björklund, E. Analytical-scale microwave-assisted extraction. J. Chromatogr. A 2000, 902, 227-250. [CrossRef]

35. Li, H.; Li, G.; Zhang, Z.X. Development of microwave assisted extraction. Chin. J. Anal. Chem. 2003, 31, 1261-1268.

36. Ondruschka, B.; Asghari, J. Microwave-assisted extraction-a state-of-the-art overview of varieties. Chimia 2006, 60, 321-325. [CrossRef]

37. Wang, L.J.; Weller, C.L. Recent advances in extraction of nutraceuticals from plants. Trends Food Sci. Technol. 2006, 17, 300-312. [CrossRef]

38. Martino, E.; Collina, S.; Rossi, D.; Bazzoni, D.; Gaggeri, R.; Bracco, F.; Azzolina, O. Influence of the extraction mode on the yield of hyperoside, vitexin and vitexin-2"-O-rhamnoside from Crataegus monogyna Jacq. (Hawthorn). Phytochem. Anal. 2008, 19, 534-540. [CrossRef] [PubMed]

39. Ge, X.L.; Shi, T.; Wang, H.; Zhang, J.; Zhang, Z.Q. Development of an aqueous polyethylene glycol-based extraction and recovery method for almond (Prunus armeniaca L.) protein. Food Anal. Methods 2016, 9, 3319-3326. [CrossRef]

40. Nescatelli, R.; Carradori, S.; Marini, F.; Caponigro, V.; Bucci, R.; De Monte, C.; Mollica, A.; Mannina, L.; Ceruso, M.; Supuran, C.T.; Secci, D. Geographical characterization by MAE-HPLC and NIR methodologies and carbonic anhydrase inhibition of Saffron components. Food Chem. 2017, 221, 855-863. [CrossRef] [PubMed]

41. Belwal, T.; Bhatt, I.D.; Rawal, R.S.; Pande, V. Microwave-assisted extraction (MAE) conditions using polynomial design for improving antioxidant phytochemicals in Berberis asiatica Roxb. ex DC. leaves. Ind. Crop. Prod. 2017, 95, 393-403. [CrossRef]

42. Liu, Z.Z.; Qiao, L.; Gu, H.Y.; Yang, F.J.; Yang, L. Development of brönsted acidic ionic liquid based microwave assisted method for simultaneous extraction of pectin and naringin from pomelo peels. Sep. Purif. Technol. 2017, 172, 326-337. [CrossRef]

43. Hemwimon, S.; Pavasant, P.; Shotipruk, A. Microwave-assisted extraction of antioxidative anthraquinones from roots of Morinda citrifolia. Sep. Purif. Technol. 2007, 54, 44-50. [CrossRef]

44. Ren, Y.; Chen, Y.; Hu, B.H.; Wu, H.; Lai, F.R.; Li, X.F. Microwave-assisted extraction and a new determination method for total steroid saponins from Dioscorea zingiberensis C.H. Wright. Steroids 2015, 104, 145-152. [CrossRef] [PubMed]

45. Dong, J.; Liu, Y.B.; Liang, Z.S.; Wang, W.L. Investigation on ultrasound-assisted extraction of salvianolic acid B from Salvia miltiorrhiza root. Ultrason. Sonochem. 2010, 17, 61-65. [CrossRef] [PubMed]

46. Martino, E.; Ramaiola, I.; Urbano, M.; Bracco, F.; Collina, S. Microwave-assisted extraction of coumarin and related compounds from Melilotus officinalis (L.) Pallas as an alternative to Soxhlet and ultrasound-assisted extraction. J. Chromatogr. A 2006, 1125, 147-151. [CrossRef] [PubMed] 
47. Sun, Y.S.; Liu, Z.B.; Wang, J.H. Ultrasound-assisted extraction of five isoflavones from Iris tectorum Maxim. Sep. Purif. Technol. 2011, 78, 49-54. [CrossRef]

48. Golmakani, M.T.; Rezaei, K. Comparison of microwave-assisted hydrodistillation with the traditional hydrodistillation method in the extraction of essential oils from Thymus vulgaris L. Food Chem. 2008, 109, 925-930. [CrossRef] [PubMed]

Sample Availability: Sample of chickpeasaponin B1 is available from the authors.

(C) 2017 by the authors. Licensee MDPI, Basel, Switzerland. This article is an open access article distributed under the terms and conditions of the Creative Commons Attribution (CC BY) license (http:/ / creativecommons.org/licenses/by/4.0/). 